\title{
Augmentation of thermal power stations with solar energy
}

\author{
B R PAI \\ Karnataka State Council for Science \& Technology, Bangalore 560012, \\ India and \\ Propulsion Division, National Aeronautical Laboratory, P. B. No. 1779, \\ Bangalore 560017, India
}

MS received 8 February 1991; revised 1 August 1991

\begin{abstract}
A new concept of integration of a solar concentrator field with a modern thermal power station is proposed. Such a configuration would utilise the existing equipment and infrastructure as a base load facility and solar energy to reduce the fuel consumption during periods of insolation. The methodology suggested involves feed water heating using a solar concentrator field and consequent reduction of steam extraction presently used for the purpose.

Study of retrofit to a $210-\mathrm{MW}$ coal-fired plant indicates that saving of fuel upto $24.5 \%$ during periods of insolation can be achieved for feed water heating upto the present level, which is to a temperature of $241^{\circ} \mathrm{C}$. The annual saving in coal would be around 47,000 tons at an estimated cost of about Rs. 3 crores. A doubling of the savings, by heating to a higher temperature level of $330^{\circ} \mathrm{C}$, is feasible with presently available solar technology.

Areas needing detailed study for achieving such an integration are indicated. The control system required to allow for fluctuations in the solar output is outlined. It is felt that the proposed system, where solar energy contributes a small but significant fraction of the total output of the plant, would be easier to control than one where the total energy is provided by solar radiation.

A preliminary estimate indicates that the proposed system may cost about half of a stand-alone solar plant with back-up fuel and with the same solar input. However site-specific studies need to be carried out to confirm these figures.
\end{abstract}

Keywords. Fuel-saving in thermal stations; solar energy; solar concentrator; feed water heating.

\section{Introduction}

Large-scale power generation from solar energy is now a reality. Power generation in the range of 5-30 MW has been achieved and the technology appears to have 
matured to a level where sustained power generation can be undertaken. In California, several solar electric generating systems (SEGS) have been installed by the Luz Company (Jaffe et al 1987). The first one was rated at $13.8 \mathrm{MW}$ and subsequent ones (SEGS II-IV) at $30 \mathrm{MWe}$ net (details in appendix A). Recently a $60-\mathrm{MW}$ plant has been operated and a $80-\mathrm{MW}$ unit is under construction (Schrocder 1991). These systems employ large parabolic trough collectors which track the sun and heat a special "heat-transfer fluid" to about $330^{\circ} \mathrm{C}$. This in turn heats water in a 'solar boiler' to generate steam which is expanded in a special steam turbine. A key element in the set-up is a back-up system which involves an auxiliary boiler with a separate fuel, generally natural gas, which provides high quality steam and ensures a steady power output from the system irrespective of fluctuations in the solar output. The parabolic trough collectors used in these systems are large, ranging in area from $47.1 \mathrm{~m} \times 5.0 \mathrm{~m}$ used in SEGS III and IV to $95.2 \mathrm{~m} \times 5.76 \mathrm{~m}$ for the proposed SEGS VII. The collectors are constructed from pre-formed mirror segments, supported in a truss. The reliability and availability of the plants, according to Jaffe et al (1987), is quite impressive (above $90 \%$ on tracking days). Thus it appears that parabolic trough technology has matured to a point where it can be considered for commercial application.

The costs associated with such systems are still high compared to conventional systems. For example, Jaffe et al (1987), mention US $\$ 100 \mathrm{M}$ for a plant of $30 \mathrm{MW}$. This works out to Rs. 8 crores per MW, which is about 3 times the cost of a conventional thermal plant. Apart from the high developmental cost of such new technology, it should be noted that a complete back-up system with auxiliary boiler, a special turbine with a dual pressure inlet and a complex control system are needed to achieve steady operation. Thus, to overcome periods of passing clouds, the auxiliary boiler would have to supply additional energy to maintain constant output. On days when solar radiation is low, the auxiliary source would need to meet the full load. Further it may be noted that the steam conditions achievable from the solar boiler with this technology $\left(330^{\circ} \mathrm{C}, 43.4 \mathrm{bar}, 1\right.$ bar $\left.=10^{5} \mathrm{~Pa}\right)$ are far inferior to those encountered in a typical modern thermal plant $\left(535^{\circ} \mathrm{C}, 150\right.$ bar $)$. Better steam conditions may be obtained in the tower concept employing reflections from an array of mirrors on to a central tower. However this technology is more complex and has not yet been demonstrated at the power levels achieved with the parabolic trough systems.

While the concept of a power plant operating totally on solar energy does have a certain puristic appeal, it may not be the most practical or cost effective scheme, for reasons mentioned above. A better proposition may be to integrate solar energy systems with alternative systems with a view to obtain overall benefits at present levels of available technology.

\section{Proposed methodology}

One way to overcome the problems mentioned above would be to integrate a solar concentrator field with a conventional thermal power station to obtain a portion of the energy required from the solar source. Such an integration would have three major advantages over the 'stand-alone' approach. First, the capital cost associated with the back-up system would be eliminated, since the basic system-cost would remain unaltered. Only retrofitting costs and the cost of the collector field and the control system would be involved. Second, limitations of the collector field could be 
taken into account (in terms of temperature and pressure) to see that the overall thermodynamic efficiency is not affected. Third, since only a small fraction of the power plant is affected (say, typically $15 \%$ of the boiler fuel flow), the control problem associated with fluctuating insolation will be much lower than for the stand-alone system.

Before explaining the proposed scheme of integration of solar systems it would be appropriate to outline the salient features of a typical thermal power plant.

\subsection{Conventional thermal power plant}

A modern thermal plant is a highly developed and optimal plant operating on the Rankine cycle. A great deal of development has taken place to obtain high levels of efficiency and reliability. Figure 1 shows the circuit and main equipment used in a typical plant and figure 2 shows the thermodynamic cycle employed in the $T-S$ diagram. It may be noted that steam is reheated in the boiler after expansion in the HP turbine. Further, steam is extracted at 6 points from the turbine (one after the HP turbine, two from the IP turbine and three from the LP turbine) to heat the feed water after condensation and before entering the boiler. The total steam extraction is approximately $30 \%$ of the boiler flow. The extracted steam is used for regenerative heating of the condensed feed water from a temperature of about $50^{\circ} \mathrm{C}$ upto a temperature of about $238^{\circ} \mathrm{C}$. This heating is done in a series of 6 heat exchangers as shown in figure 1 . One of these is a direct contact heat exchanger and serves as the deaerator (DA). The rest are of shell-and-tube type and are designated HP or LP heaters as appropriate. The drain-offs from the various heaters are collected and fed back into the circuit after the condensor.

Control of the power plant is achieved through a combination of different systems, namely control of the fuel input to the boiler (to maintain set pressure at the exit), regulating valves upstream of the HP and IP cylinders (to govern the r.p.m. of the

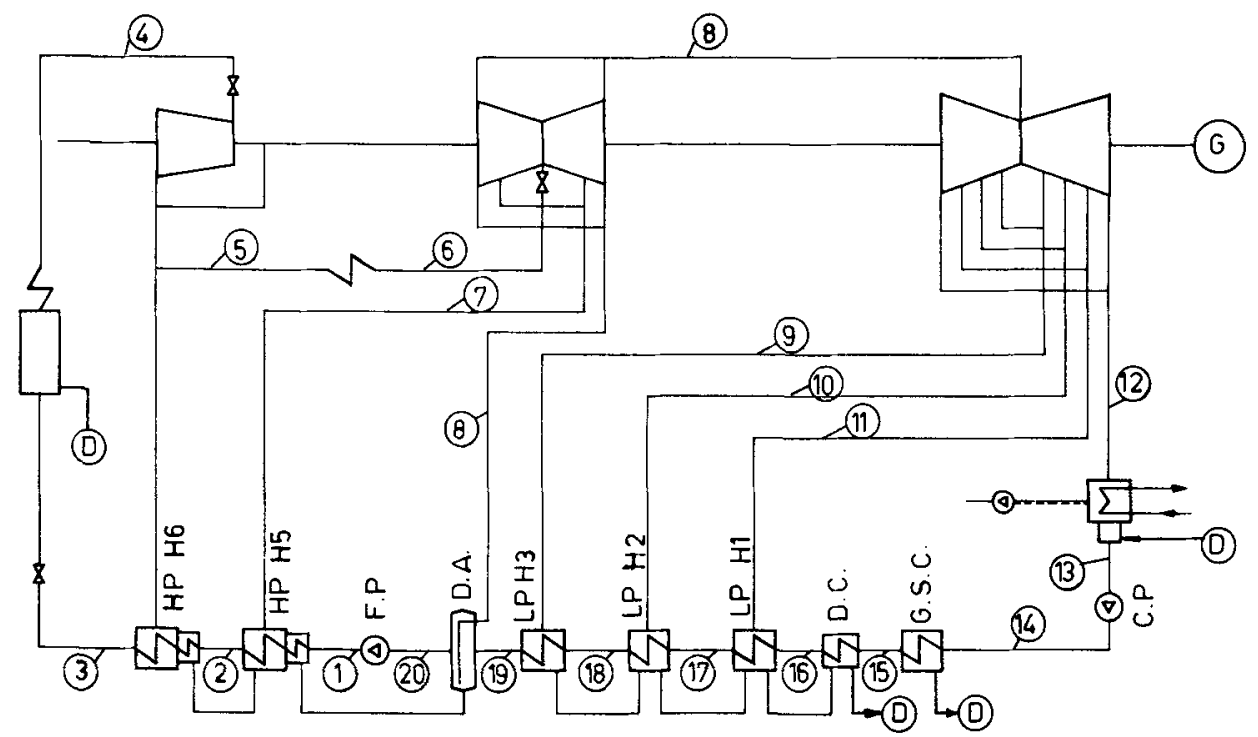

Figure 1. Schematic diagram of conventional thermal power station. 


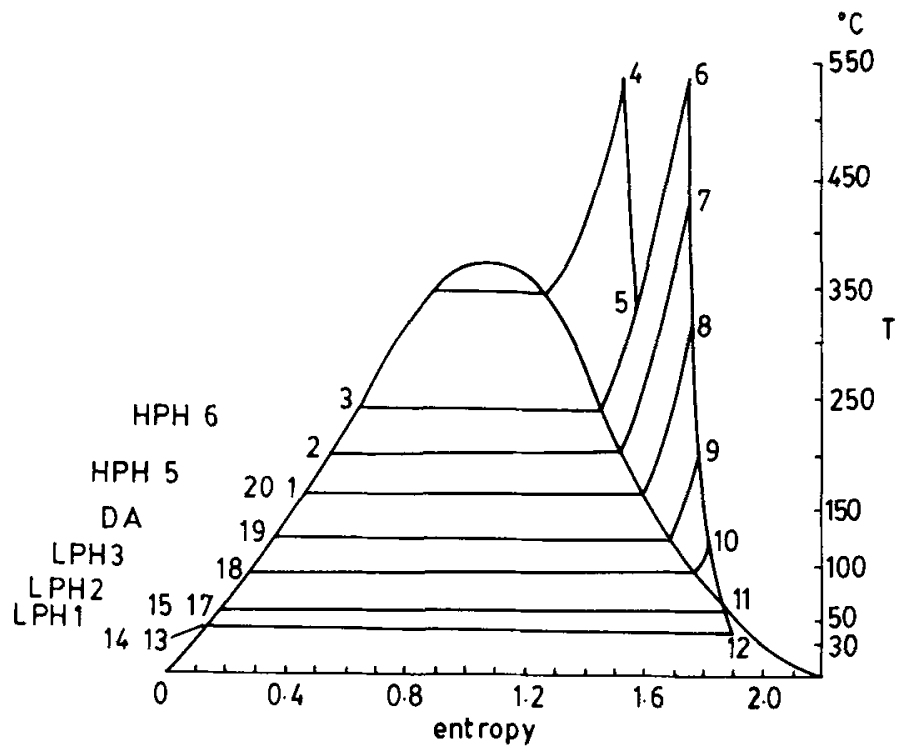

Figure 2. T-S diagram of conventional thermal power plant.

turbine) etc. The flow rate of the feed water can be controlled by a valve downstream of the feed water pump (FP).

\subsection{Integration of solar feed water heating}

The proposed arrangement for incorporating a solar feed water heating system in the thermal power plant of figure 1 is indicated in figure 3 . Shell-and-tube heat exchangers are interspersed before each of $3 \mathrm{LP}$ heaters and $2 \mathrm{HP}$ heaters. Another heat exchanger (SHPH 7) is arranged downstrem of the HP heater 6. All these additional heat exchangers are connected in series on their shell side in a circuit which is filled with the heat transfer fluid. The circuit is completed through the solar collector field, a circulating pump and a control valve. The heat transfer fluid flows counter to the feed water, in order to provide a counter flow heat exchange for high heat transfer efficiency.

Another feature of the arrangement is that the deaerator system is retained without alteration, so that deaeration function is available all the time.

An important feature of the proposed arrangement is that feed water can be heated either by the extraction steam or the heat transfer fluid or by both, depending on their flow rates and the temperature differentials in the system. For example, during periods of low insolation, the flow of the heat transfer fluid would be switched off (or maintained at a minimum value). Steam extractions from all the extraction points would be at their normal rates and the feed water heated as during normal conventional operation. On the other hand, during periods of insolation, when the heat transfer fluid would be at the desired temperature, circulation of the fluid through the circuit will ensure the required feed water heating, with the steam extractions reduced or switched off completely by means of stop valves in the steam circuit.

\subsection{Operation of plant with solar augmentation}

During nights and non-insolation periods, the plant operates in the base mode, with normal steam extractions for regenerative heating. The heat transfer fluid in the solar 


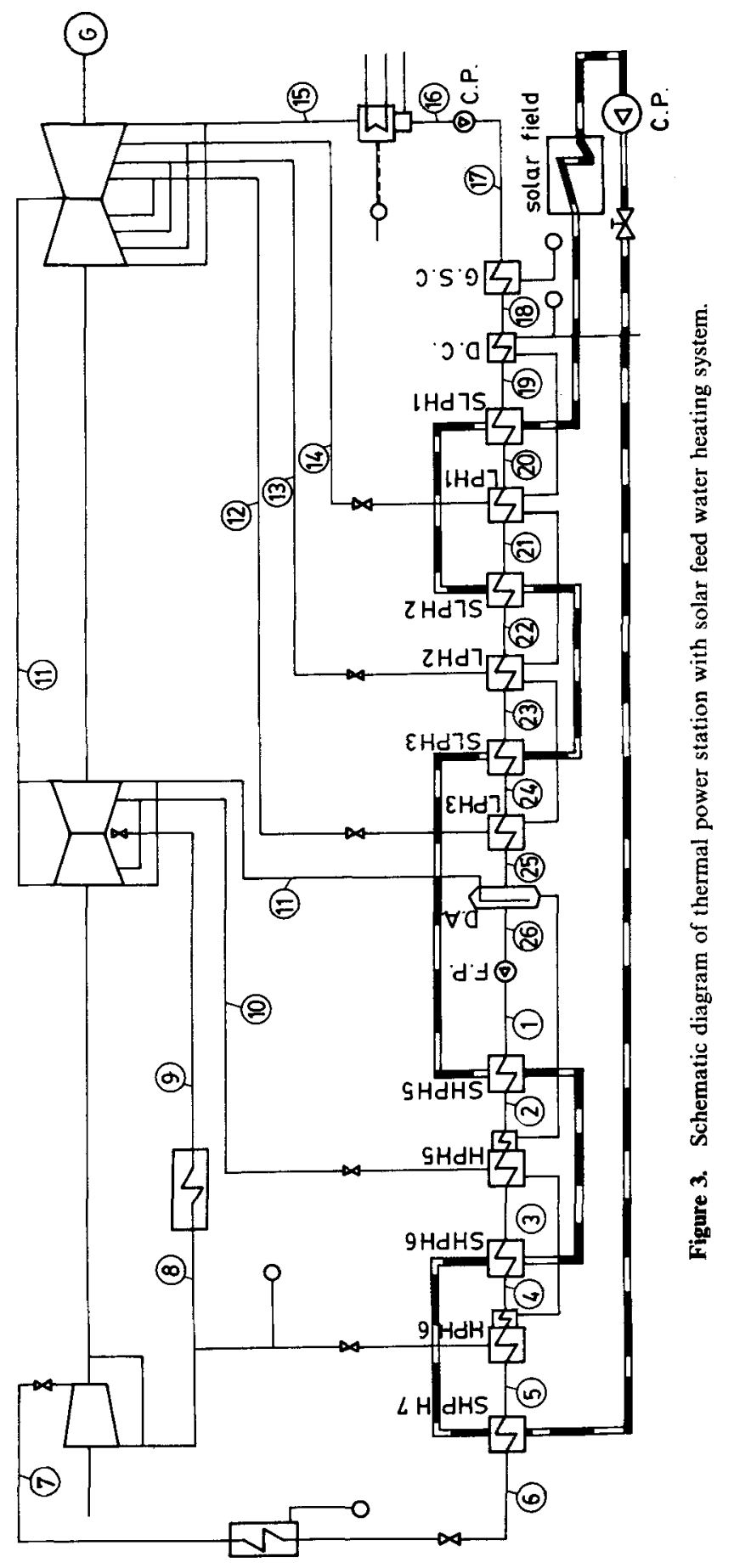


circuit is circulated at a certain minimum flow rate. As the sun rises, the solar concentrators start tracking the sun and the temperature of the heat transfer fluid starts rising. When its temperature has risen to a value high enough to ensure positive heat transfer to the feed water, the flow rate of the heat transfer circuit is increased. Simultaneously, the steam extraction flows are reduced. Since the system is now receiving energy from the solar fluid, the fuel control system of the boiler reduces the fossil fuel input to maintain the boiler exif conditions. Finally the feed water flow rate is reduced to maintain the electrical output at the base load value. During the day this configuration continues. Small fluctuations in solar insolation would be compensated for by steam extraction from one or more points to maintain the feed water temperature. Thus solar energy could be harnessed to reduce the fossil fuel consumption. During the evening, as the solar insolation reduces, the flow rate of the heat transfer fluid is reduced and the steam extraction increased, to get back to the base state. It may be noted that microprocessor-based control of the solar plant to cater to changing insolation is a standard feature of presently engineered solar plants. Extension of such microprocessor control to one or more of the steam extraction flows would be additional features to be developed. It is understood that motorised valves are already provided in power stations for modulation of steam extraction flows.

\section{Estimation of equipment capacities and potential benefits}

As an illustrative example, a typical $210-\mathrm{MW}$ base load coal-fired thermal power station is considered for retrofit with solar feed water heating. The basic (premod) configuration is shown in figure 1 and the thermodynamic cycle in figure 2 . The schematic of the retrofitted plant is shown in figure 3 and the thermodynamic cycle in figure 4.

First, the heat supplied by the regenerative heating in the original cycle is estimated

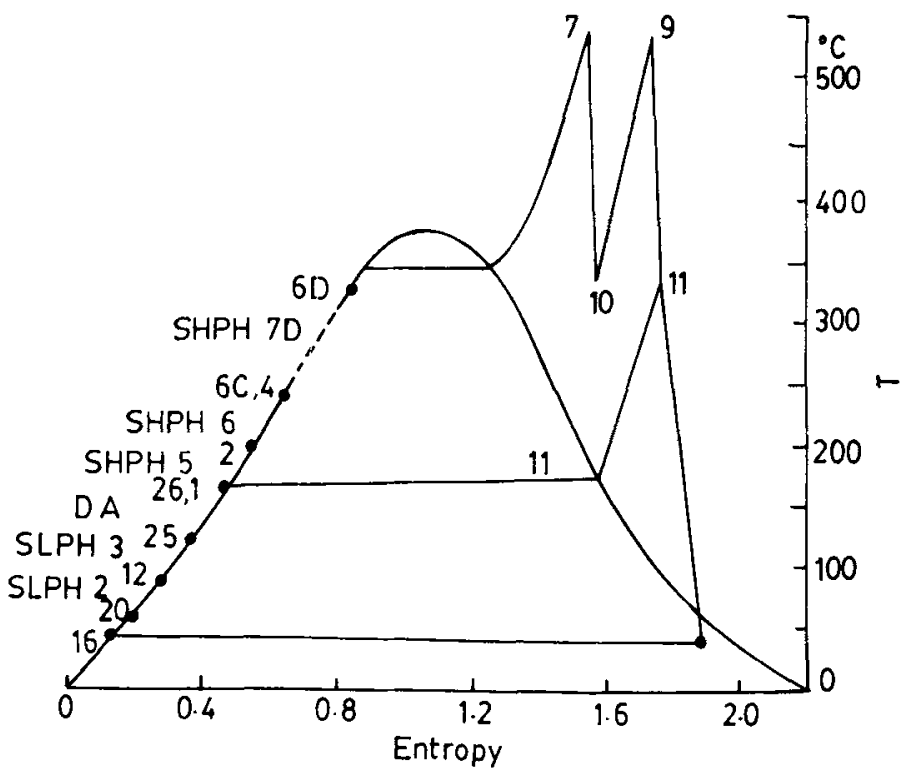

Figure 4. $T-S$ diagram of thermal plant with solar feed water heating. 
Table 1. Case A: (conventional basic cycle, $210 \mathrm{MWe}$ ) heating in a regenerative system.

\begin{tabular}{|c|c|c|c|c|c|c|}
\hline & $\begin{array}{c}m \\
(\mathrm{t} / \mathrm{h})\end{array}$ & $\begin{array}{c}h_{\mathrm{jn}} \\
(\mathrm{kcal} / \mathrm{kg})\end{array}$ & $\begin{array}{c}h_{\text {out }} \\
(\mathrm{kcal} / \mathrm{kg})\end{array}$ & $\begin{array}{c}h \\
(\mathrm{kcal} / \mathrm{kg})\end{array}$ & $\begin{array}{c}Q \\
(\mathrm{MW})\end{array}$ & \\
\hline G. steam cooler & 505 & $46 \cdot 7$ & $47 \cdot 0$ & 0.3 & $0 \cdot 2$ & \multirow{7}{*}{$43 \cdot 5$} \\
\hline Drain cooler & 505 & $47 \cdot 0$ & 47.9 & 0.9 & 0.5 & \\
\hline LHP 1 & 505 & $47 \cdot 0$ & $56 \cdot 5$ & $8 \cdot 6$ & $5 \cdot 1)$ & \\
\hline LPH 2 & 505 & $56 \cdot 5$ & 90.4 & $33 \cdot 9$ & $19.9\}$ & \\
\hline LPH 3 & 505 & $90-4$ & $121 \cdot 0$ & 31.6 & 18.6 & \\
\hline Deaerator & $(505)$ & $121 \cdot 0$ & $162 \cdot 2$ & $41 \cdot 2$ & $(24-2)$ & \\
\hline Boiler FP & 628 & $162 \cdot 2$ & $168 \cdot 2$ & 6.0 & $4 \cdot 4$ & \\
\hline HP H5 & 628 & $168 \cdot 2$ & $203 \cdot 2$ & 35.0 & $25 \cdot 5\}$ & \multirow{2}{*}{$59 \cdot 4$} \\
\hline HP Ho & 628 & $203 \cdot 2$ & $249 \cdot 6$ & $46 \cdot 4$ & 33.9 & \\
\hline Total & & & & & $132 \cdot 3$ & $102 \cdot 9$ \\
\hline
\end{tabular}

(case A). Figure 5 shows the heat balance diagram for this situation. The heat pick-ups in the regenerative line is as shown in table 1.

Thus the total enthalpy pick up is $132 \mathrm{MW}$ out of which $103 \mathrm{MW}$ occurs in the LP and HP heaters.

Next, solar heating of the feed water is considered. The only steam extraction is for the deaerator after the IP cylinder. Since the flows through the turbine are altered, the stages would be operating at different operating points. The steam flow rate, in the absence of extraction would settle down to a value lower than with extraction, such as to produce the same net power from the generator. To obtain this value rigorously, the off-design performance characteristics of each of the turbine cylinders (namely HP, IP and LP) are needed. In the absence of this information, the case where both the HP heaters are bypassed is examined, since data are available in this case. Figure 6 shows the heat balance diagram for this (case B).

The net electrical output for cases $A$ and $B$ are the same, namely $210 \mathrm{MW}$. In case $B$ there is no steam extraction after the HP cylinder or the IP 1st bleed point, but the deaerator bleed is maintained. The expansion process in the two cases A and B are as in table 2 . It is noted that the overall pressure drop remains the same. The enthalpy drops are also nearly the same: about $2 \%$ less in case $B$.

Thus for the case with solar feed water heating, (case C) we may assume that the enthalpy drops across each turbine cylinder are the same as for case B, where the HP heaters are bypassed.

\subsection{Mass flow rates}

The mass flow rates are estimated as follows:

$H P$ cylinder: It can be seen from figures 5 and 6 that $2.6 \%$ of the steam flow comes out from the first leak off point into the cold reheat steam line and does not expand through the HP turbine. Also, the gland losses are about $0.9 \%$. Consequently it is assumed that

$$
\dot{m}_{\mathrm{HP}}=0.965 \dot{m}_{b}
$$

where $\dot{m}_{b}$ is the flow rate through the boiler. 


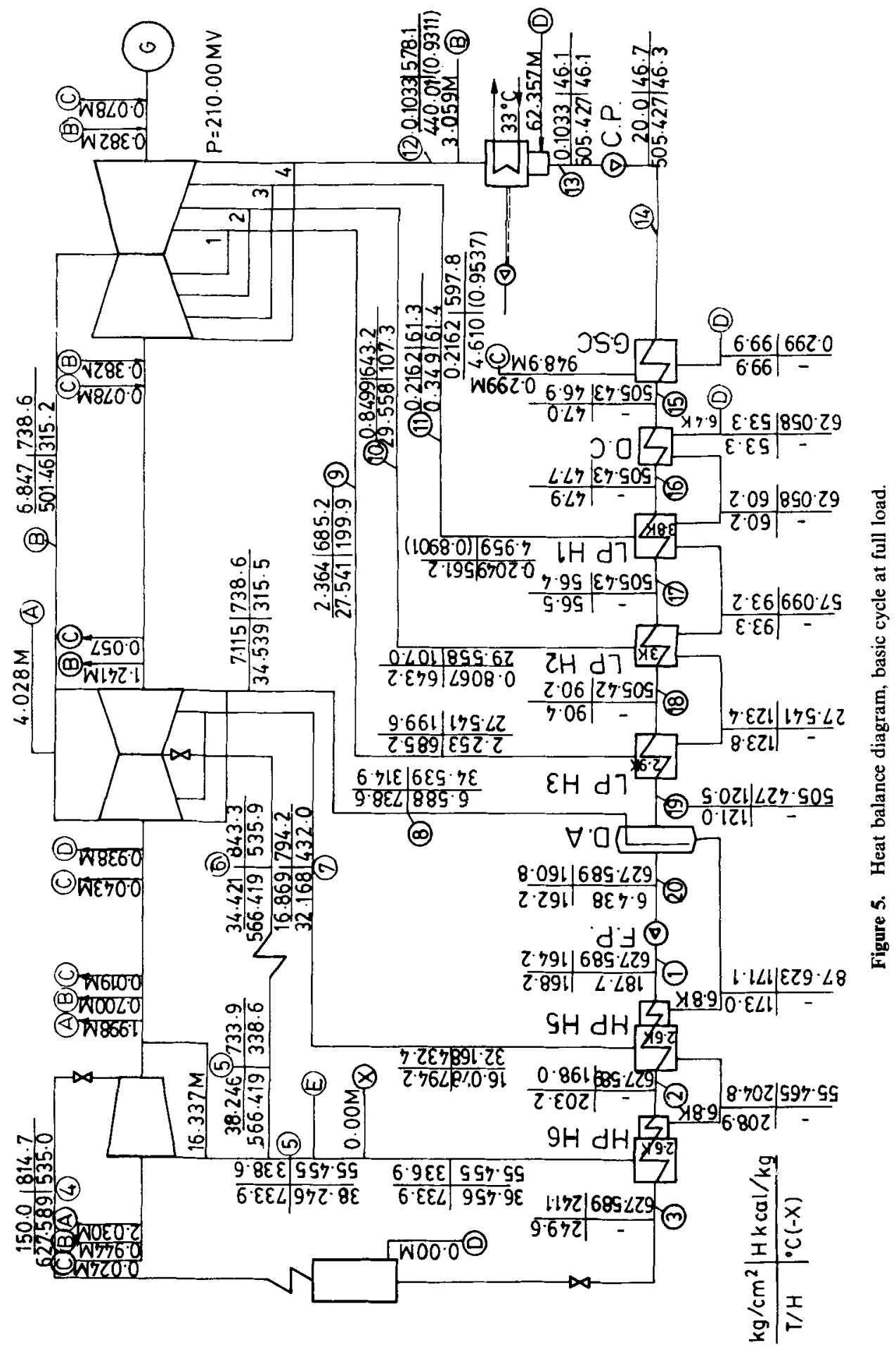




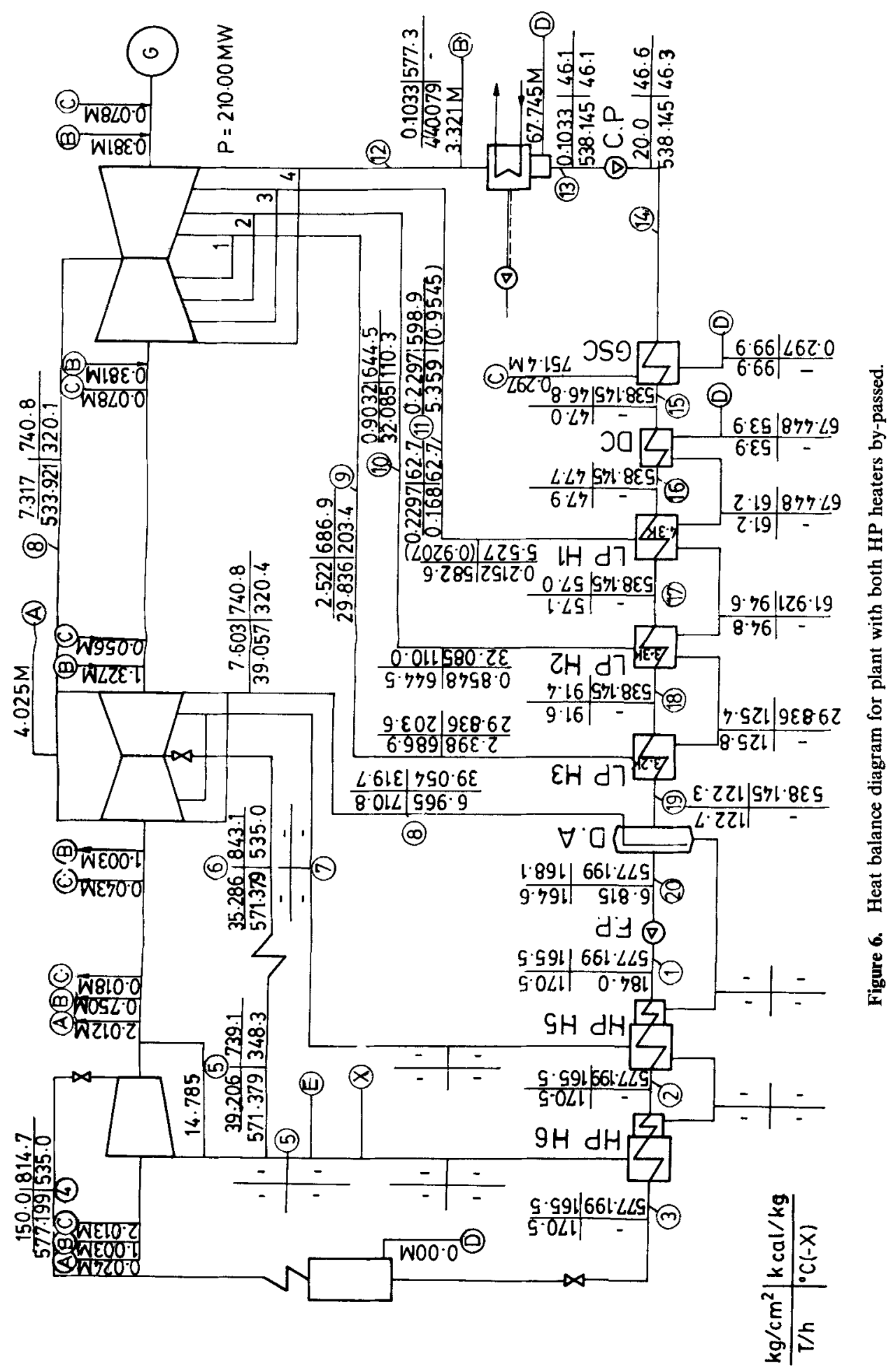


Table 2. Comparison of enthalpy and pressure drops across turbine stages for cases A and B.

\begin{tabular}{|c|c|c|c|c|c|c|c|c|}
\hline & \multicolumn{4}{|c|}{ Case A } & \multicolumn{4}{|c|}{ Case B } \\
\hline & $\begin{array}{c}h_{\mathrm{in}} \\
(\mathrm{kcal} / \mathrm{kg})\end{array}$ & $\begin{array}{c}h_{\text {out }} \\
(\mathrm{kcal} / \mathrm{kg})\end{array}$ & $\begin{array}{c}\Delta h \\
(\mathrm{kcal} / \mathrm{kg})\end{array}$ & $\begin{array}{c}P_{\text {in }} /(x) \\
\left(\mathrm{kg} \mathrm{cm}^{-2}\right)\end{array}$ & $\begin{array}{c}h_{\text {in }} \\
(\mathrm{kcal} / \mathrm{kg} \text { ) }\end{array}$ & $\begin{array}{c}h_{\text {out }} \\
(\mathrm{kcal} / \mathrm{kg})\end{array}$ & $\begin{array}{c}\Delta h \\
(\mathrm{kcal} / \mathrm{kg})\end{array}$ & $\begin{array}{c}p_{\text {in }} /(x) \\
\left(\mathrm{kg} / \mathrm{cm}^{2}\right)\end{array}$ \\
\hline HP Cyl & $814 \cdot 7$ & 733.9 & $80-8$ & 150 & 814.7 & $739 \cdot 1$ & $75 \cdot 6$ & $150 \cdot 0$ \\
\hline IP 1 & $843 \cdot 3$ & $794 \cdot 2$ & $49 \cdot 1$ & $34 \cdot 4$ & $843 \cdot 1$ & - & $102 \cdot 3$ & $35 \cdot 3$ \\
\hline IP 2 & 794.2 & 738.6 & $55 \cdot 6$ & 16.9 & - & 740.8 & & \\
\hline LP 1 & 738.6 & $685 \cdot 2$ & $53 \cdot 4$ & 6.8 & $740 \cdot 8$ & 686.9 & 53.9 & $7 \cdot 3$ \\
\hline LP 2 & $685 \cdot 2$ & 643.2 & 42.0 & $2 \cdot 4$ & 686.9 & 644.5 & $42 \cdot 4$ & $2 \cdot 5$ \\
\hline LP 3 & $643 \cdot 2$ & 597.8 & $45 \cdot 4$ & $(0.9)$ & 644.5 & 598.9 & $45 \cdot 6$ & 0.9 \\
\hline \multirow[t]{2}{*}{ LP 4} & 597.8 & $578 \cdot 1$ & $19 \cdot 7$ & 0.2 & 598.9 & $577 \cdot 3$ & $21 \cdot 6$ & 0.2 \\
\hline & & & & $0 \cdot 1$ & & & & 0.1 \\
\hline Total & & & 348 & & & & $341 \cdot 4$ & \\
\hline
\end{tabular}

IP cylinder: The losses through the gland are about $0 \cdot 36 \%$. Further, some of the gland steam from HP is returned in this flow. Hence,

$$
\begin{aligned}
\dot{m}_{\mathrm{IP}} & =\left(\dot{m}_{\mathrm{HP}}+\dot{m}_{\text {leak off }}\right) \times 0.9964 \\
& =0.987 \dot{m}_{b} .
\end{aligned}
$$

LP cylinder: It may be noted that in the absence of steam extraction to HP heater 5 , the mass flow through the LP cylinder would be related to the mass flow through the IP cylinder through the relation,

$$
\dot{m}_{\mathrm{LP}}=\dot{m}_{\mathrm{IP}}-\dot{m}_{\mathrm{DA}}+\dot{m}_{A}-\dot{m}_{(C) \mathrm{LP}} \text {, }
$$

where $\dot{m}_{\mathrm{DA}}$ is the steam flow extracted in the deaerator, $\dot{m}_{\mathrm{A}}$ is the gland steam returned from the HP section and $\dot{m}_{(C) L P}$ is the leakage from the LP cylinder glands. Typically, assuming the deaerator bleed flow to be $7 \%$, and $\dot{m}_{\mathrm{A}}$ and $\dot{m}_{(C) L P}$ to be 0.64 and $0.025 \%$ of the boiler flow, the $\dot{m}_{\mathrm{LP}}$ can be taken as $0.9235 \dot{m}_{b}$.

It is also assumed that during solar augmentation, the net electrical output is $210 \mathrm{MW}$ and that steam turbine efficiency is same as in case B. The turbine power output can be expressed as

$$
\dot{m}_{\mathrm{HP}} \Delta h_{\mathrm{HP}}+\dot{m}_{\mathrm{IP}} \Delta h_{\mathrm{IP}}+\dot{m}_{\mathrm{LP}} \Delta h_{\mathrm{LP}}=P_{\mathrm{turb}} \text {. }
$$

Substituting expressions for the individual mass flow rates from (1) to (3) and taking the enthalpy drops from case B (figure 6), the boiler feed rate in case of solar augmentation works out to $560 \cdot 2 \mathrm{t} / \mathrm{h}$. This implies a reduction of feed water rate of $10.7 \%$ during solar augmentation.

To determine the energy savings, the temperature to which the feed water is heated by solar radiation has to be determined. Two limiting cases (C and D) are considered, namely:

Case $C$ : The feed water is heated by the solar field from the condensor outlet temperature $\left(47 \cdot 9^{\circ} \mathrm{C}\right)$ to the present level achieved by regenerative heating, i.e. $241^{\circ} \mathrm{C}$.

Case D: The feed water is heated upto $328^{\circ} \mathrm{C}$ by the solar field. This is the level presently achievable with the parabolic trough technology. It can be seen from the 
Table 3. Energy flows from fossil fuel.

\begin{tabular}{|c|c|c|c|c|c|}
\hline \multirow[b]{2}{*}{ Case A } & \multirow{2}{*}{$\begin{array}{c}\begin{array}{c}\text { Feed water } \\
\text { flow } m_{b}(t / h)\end{array} \\
628\end{array}$} & \multicolumn{2}{|c|}{$\begin{array}{c}h \text { boiler } \\
(\mathrm{kcal} / \mathrm{kg})\end{array}$} & \multirow{2}{*}{$\frac{\begin{array}{c}Q \text { boiler } \\
\text { (MW) }\end{array}}{412}$} & \multirow{2}{*}{$\begin{array}{c}\begin{array}{c}\text { Relative } \\
\text { fuel flow }\end{array} \\
1.00\end{array}$} \\
\hline & & $\begin{array}{l}814 \cdot 7 \\
249 \cdot 6\end{array}$ & $565 \cdot 1$ & & \\
\hline Case B & 577 & $\begin{array}{l}814 \cdot 7 \\
170 \cdot 5\end{array}$ & $644 \cdot 2$ & 432 & 1.05 \\
\hline Case C & 560 & $\begin{array}{l}814 \cdot 7 \\
249 \cdot 6\end{array}$ & $565 \cdot 1$ & 368 & 0.89 \\
\hline Case D & 560 & $\begin{array}{r}814 \cdot 7 \\
* 343 \cdot 5\end{array}$ & $471 \cdot 3$ & 307 & 0.74 \\
\hline
\end{tabular}

* The enthalpy at boiler inlet is calculated as follows. The specific heat for the feed water in the terminal heater SHPH 7 is taken as 1.08. Then $\Delta h=1.08 \times(328-241 \cdot 1)=93.9 \mathrm{kcal}$. Hence enthalpy at boiler entry $=249 \cdot 6+93 \cdot 9=343 \cdot 5 \mathrm{kcal} / \mathrm{kg}$.

$T-S$ diagram (figure 4) that this level of temperature would not cause boiling in the feed water heating section. However, the economiser section in the boiler may have to be by-passed to prevent boiling there.

It is to be noted that any intermediate cases between the levels for Case C and D are feasible, depending on the heater design of the terminal heater SHPH 7.

The thermal input required to be obtained from the fossil fuel in the boiler can be now worked out for the above cases, as given in table 3 .

It is seen that 10.7 to $25.6 \%$ reduction in fossil fuel input is obtained depending on the solar input available.

The estimated heat loads on the solar-heated heat exchangers are shown in table 4.

\subsection{Estimation of solar collector field}

An estimate of the solar collector field is made from the heat loads indicated in table 4 for the limiting cases case $\mathrm{C}$ and case $\mathrm{D}$.

In Jaffe et al (1987), the average annual thermal efficiency for the LS-3 collector assembly is stated to be $53 \%$. In this case, the heat transfer fluid is heated from 248 to $349^{\circ} \mathrm{C}$. Since in the proposed system, heating at a lower temperature range is

Table 4. Heat loads for solar-heated feed water.

\begin{tabular}{|c|c|c|c|c|c|}
\hline Heaters & $\begin{array}{c}\text { Mass flow } \\
(\mathrm{t} / \mathrm{h})\end{array}$ & $\begin{array}{c}\Delta h \\
(\mathrm{kcal} / \mathrm{kg})\end{array}$ & $\begin{array}{c}t_{\text {in }} \\
\left({ }^{\circ} \mathrm{C}\right)\end{array}$ & $\begin{array}{c}t_{\text {out }} \\
\left({ }^{\circ} \mathrm{C}\right)\end{array}$ & $\underset{(\mathrm{MW})}{Q}$ \\
\hline SLPH 1 & $517 \cdot 332$ & $8 \cdot 6$ & $47 \cdot 7$ & $56 \cdot 4$ & $5 \cdot 173$ \\
\hline SLPH 2 & $517 \cdot 332$ & 33.9 & $56 \cdot 4$ & $90 \cdot 2$ & $20 \cdot 392$ \\
\hline SLPH 3 & $577 \cdot 332$ & $30 \cdot 6$ & $90 \cdot 2$ & $120 \cdot 5$ & $18 \cdot 407$ \\
\hline SHPH 5 & $556 \cdot 545$ & $35 \cdot 0$ & $164 \cdot 2$ & $198 \cdot 0$ & 22.650 \\
\hline SHPH 6 & $556 \cdot 545$ & $46 \cdot 4$ & 198.0 & $241 \cdot 1$ & $30-028$ \\
\hline SHPH 7 (case C) & 556.545 & 0.0 & $241 \cdot 1$ & $241 \cdot 1$ & - \\
\hline SHPH 7 (case D) & 556.545 & $140 \cdot 25$ & $241 \cdot 1$ & $328 \cdot 0$ & $90 \cdot 762$ \\
\hline
\end{tabular}

Total $($ case $C)=96.65 \mathrm{MW},($ case $\mathrm{D})=187.4 \mathrm{MW}$ 
required (i.e. 40 to $260^{\circ} \mathrm{C}$ for case $\mathrm{C}$ and 40 to $350^{\circ} \mathrm{C}$ for case $\mathrm{D}$ ), a slightly higher efficiency may be assumed, say $60 \%$ for case $C$ and $56 \%$ for case $D$.

The average insolation available to a tracked collector would depend on the site location to a considerable extent. For estimation purposes, it is surmised from maps provided in Mani \& Rangarajan (1982) that for northern Karnataka, the annual mean solar radiation is $5.8 \mathrm{kWh} / \mathrm{m}^{2}$ and the mean daily hours of sunshine is $8 \mathrm{~h}$. This implies an average insolation of $0.725 \mathrm{~kW} / \mathrm{m}^{2}$ for about $2920 \mathrm{~h}$ per year.

It is convenient to estimate the size of the collector field based on average insolation and thereafter work out the performance at other conditions such as peak insolation.

3.2a Estimation of collector field for case C: From table 4 it is noted that a thermal input of $96.65 \mathrm{MW}$ needs to be obtained from the collector field. With the above mentioned values of average solar insolation $\left(0.725 \mathrm{~kW} / \mathrm{m}^{2}\right)$ and collector efficiency $(60 \%)$, the required collector area is about $22 \cdot 2$ hectares (ha).

From table A2 it is observed that the ratio of the distance between the collector rows and the collector aperture is about 3 . Hence as an initial estimate, the land area can be taken as about thrice the collector area. For a pitch of $17.3 \mathrm{~m}$, the land area for case C works out to about 67 ha.

Peak insolation conditions - For this field the performance under peak insolation is of interest. The peak collector efficiency is stated to be $68 \%$. Assuming a peak insolation of $1 \mathrm{~kW} / \mathrm{m}^{2}$, the peak solar input would be

$$
Q_{c^{\prime}}=1.0 \times 0.68 \times 222,000=151 \mathrm{MW}(\mathrm{t}) .
$$

The feed water outlet condition for this input needs to be estimated. This case is designated $\mathrm{C}^{\prime}$. It is further assumed that the enthalpy rise across the heaters is increased proportionately.

$$
\begin{aligned}
& Q_{C}=96.65 \mathrm{MW}=\left(\Delta h_{1,2,3}\right)_{c} m_{1,2,3}+\left(\Delta h_{5,6,7}\right)_{C} m_{5,6,7}, \\
& Q_{c^{\prime}}=151=\left(\Delta h_{1,2,3}\right)_{C} m_{1,2,3}+\left(\Delta h_{5,6,7}\right)_{C} m_{5,6,7},
\end{aligned}
$$

where $\Delta h_{1,2,3}$ is the enthalpy rise across the LP heaters and $h_{5,6,7}$ is the enthalpy rise across the HP heaters.

Further, it is assumed that the enthalpy rise remains in the same proportion, namely,

$$
\left.\frac{\Delta h_{1,2,3}}{\Delta h_{5,6,7}}\right|_{C}=\left.\frac{\Delta h_{1,2,3}}{\Delta h_{5,6,7}}\right|_{c^{\prime}} .
$$

Substituting values for case $\mathrm{C}$, it is found that the enthalpy rise across the LP heaters is about $90 \%$ of the enthalpy rise across the HP heaters.

From (5), the enthalpy rise for peak insolation across the LP heaters is $114.2 \mathrm{kcal} / \mathrm{kg}$ and across the HP heaters is $127.2 \mathrm{kcal} / \mathrm{kg}$. It is reasonable to assume that the enthalpy rise $(47.2 \mathrm{kcal} / \mathrm{kg})$ across the deaerator and the feed water pump remain unaltered with changing insolation. Thus the enthalpy rise in the feed water line at peak insolation is computed as the sum of the enthalpy gains in the LP and HP heaters, deaerator and feed pump $=288.6 \mathrm{kcal} / \mathrm{kg}$. Since the enthalpy at the inlet to the feed heating system is $47.9 \mathrm{kcal} / \mathrm{kg}$, that at the outlet of SHPH 7 is computed to be $336.5 \mathrm{kcal} / \mathrm{kg}$, and since the enthalpy value at the exit during average insolation is 249.60 , an additional enthalpy rise of $86.9 \mathrm{kcal} / \mathrm{kg}$ across SHPH 7 is implied, which 
translates to an additional temperature rise of $79 \cdot 7^{\circ} \mathrm{C}$. Hence the feed water exit temperature increases to $321^{\circ} \mathrm{C}$ during peak insolation. There is a corresponding decrease in the enthalpy rise in the boiler. Taking into account the reduced mass flow rate and the reduced enthalpy rise across the boiler, the reduction in the coal feed rate works out to $24.5 \%$ compared to case $A$. It is assumed that the boiler efficiency remains constant during these changes, whereas one can expect a slight increase at lower boiler loadings.

3.2b Estimation of collector field for case $D$ on the basis of average insolation: As indicated in table 4 , in order to achieve a feed water temperature of $328^{\circ} \mathrm{C}$, a thermal input of $187.4 \mathrm{MW}$ is required. Consequently, assuming a collector efficiency of $56 \%$ and an insolation of $0.725 \mathrm{~kW} / \mathrm{m}^{2}$, a collector area of about $46 \mathrm{~h} a$ would be required. The land requirement would be approximately thrice the collector area, namely $140 \mathrm{ha}$.

On the basis of peak insolation - Since the maximum permissible temperature of the system has been attained, further increase at higher insolation is not realisable. When maximum conditions are reached, the control system has to remove some of the solar collectors, from exposure to solar radiation, in order to maintain the required temperature.

\section{Financial estimates}

Considerable detailing and estimation is required to obtain a reliable estimate of the financial and economic aspects of the proposed scheme. However, a very rough estimate is made below, just to obtain a preliminary "ball park" figure. A site-specific estimate needs to be arrived at, once the technical feasibility aspects have been established.

\subsection{Capital costs}

The retrofit cost of a solar feed water heating may be expressed as

$$
\begin{aligned}
\mathrm{CAP}= & \text { cost of collector array }(\mathrm{A}) \\
& + \text { cost of control system }(\mathrm{B}) \\
& + \text { cost of heat exchanger system }(\mathrm{C}) .
\end{aligned}
$$

The cost of collector array and associated hardware of the parabolic trough is estimated to be around $\$ 250$ per $\mathrm{m}^{2}$ (Rs. 6250 per $\mathrm{m}^{2}$ ).

The control system compising a micro-processor system, actuators, sensors, cabling etc. may cost about Rs. 1 crore.

The cost of the heat exchanger is assumed to be Rs. 2 lakhs/MW. With these assumptions, the Capital cost for case $C$ is Rs. $142 \mathrm{Cr}$, and for case D is Rs. $294 \mathrm{Cr}$.

\subsection{Coal savings}

In Karnataka, coal has to be transported over long distances from neighbouring states. For the Raichur plant, the distances are in the range 530 to $1078 \mathrm{~km}$. There is quite a wide fluctuation in the calorific value of coal ranging from 1648 to $5987 \mathrm{kcal} / \mathrm{kg}$ (say $3500 \mathrm{kcal} / \mathrm{kg}$ on an average). 
The coal consumption rate is about $0.71 \mathrm{t} / \mathrm{MWh}(\mathrm{e})$. This implies an overall generation efficiency of $34.6 \%$ for the plant. For a load of $210 \mathrm{MW}$, the coal flow rate is $210 \times 0.71=149.1 \mathrm{t} / \mathrm{h}$.

For case $\mathrm{C}$ from table 4 it is noted that coal flow is about $89.3 \%$ of the base condition, which is $133 \mathrm{t} / \mathrm{h}$. The reduction in coal flow rate is about 16 tons per hour. Assuming 2920 hours of solar augmented operation per annum, the saving would be nearly 47,000 tons, or at Rs. 650 per ton, a sum of Rs. 3.0 crores.

For case $D$, from table 4 it is seen that the coal feed rate would be about $74 \%$ of the base condition, which is $111 \mathrm{t} / \mathrm{h}$. The reduction in coal feed rate would be about $38 \mathrm{t} / \mathrm{h}$. Again, on the basis of $2920 \mathrm{~h}$ annual operation with solar augmentation, the savings would be around 111,000 tons or at Rs. 650 per ton, a sum of about Rs. $7 \cdot 2$ crores.

It may be noted that the coal consumption for each $210 \mathrm{MW}$ unit of the Raichur plant at $75 \%$ PLF is approximately 1 million tons per annum. The savings for case $\mathrm{C}$ would be about $4.7 \%$ and for case $\mathrm{D}$ about $11 \cdot 1 \%$.

\section{Discussion and suggestions}

The foregoing analysis has examined the thermodynamic feasibility of using solar heating of feed water in a modern thermal power plant employing regenerative feed water heating and reheating. Two limiting cases examined include feed water heating to the present level (case $C$ ) and to the maximum level feasible using an intermediary heat transfer fluid (case D). Any intermediate level would also be feasible. Figure 7

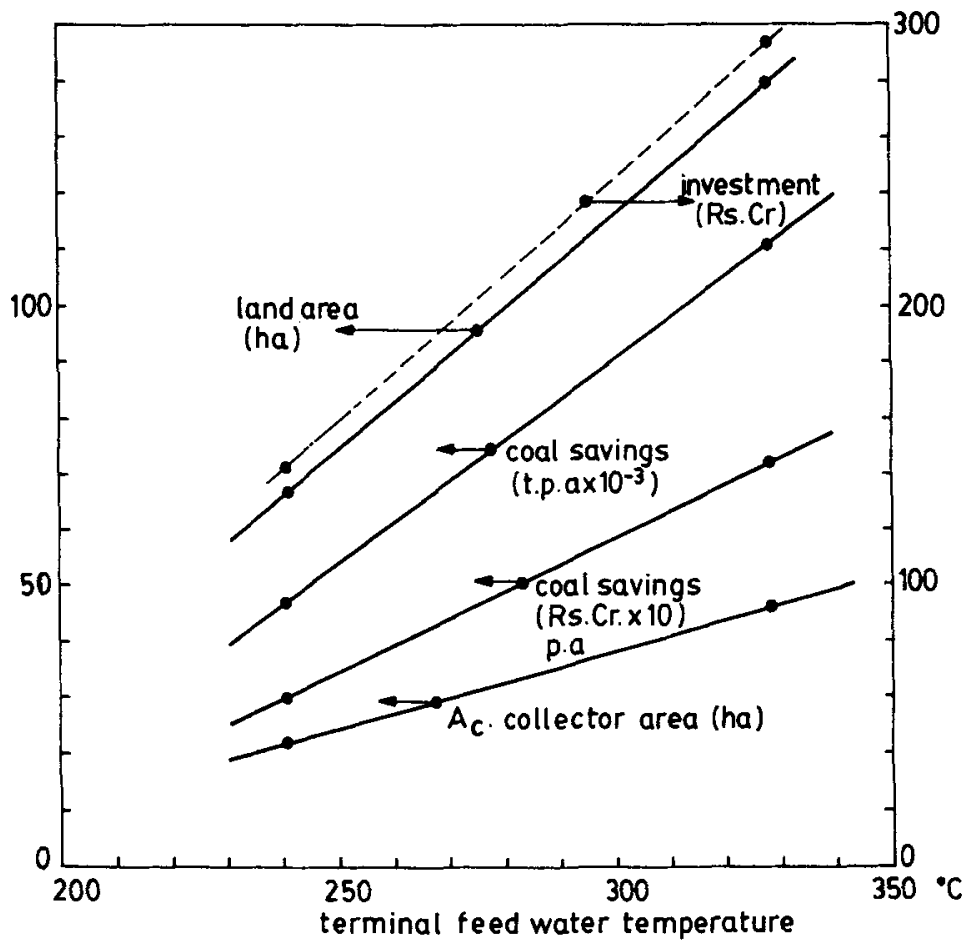

Figure 7. Influence of feed water terminal temperature on solar feed water heating system. (Cr-crores; t.p.a. tonnes per annum.) 
summarises the major parameters, namely the collector area, land requirement, investment (very approximate) and the coal saving.

Retrofitting an existing plant for solar augmentation to near about the present level of feed water heating does not appear to present any thermodynamic difficulties. Savings in coal appear to be attractive, particularly if coal has to be hauled over a long distance, in addition to benefits such as reduced pollution, reduced waste disposal problems etc. The land requirements are quite modest: the area required works out to be only $10-20 \%$ of the land area earmarked for ash dumping at the Raichur plant.

One point which needs further examination is the condensor mass flow load. Compared to the standard case (case A), cases C and D show an increase of about $17.4 \%$ in the condensor flow rate, due to the increased turbine flow rate. Case $B$ indicates that the system at present is capable of taking up a $6.2 \%$ increase without significant penalty.

A major developmental activity required is that of a control system which can provide smooth interfacing of the solar energy system with the power plant practice. This would appear to be feasible. Again plant specific data would be needed to obtain parameters such as rate of change of insolation during passing clouds etc., so that suitable control systems can be developed. Basically a coupling system would need to be introduced such that steam extraction from the turbine can be regulated to maintain a closely controlled feed water temperature for evening out fluctuations due to changing insolation. Some control would be also possible by control of the solar field itself, by varying the flow rate of the heat transfer fluid and by changing the collector tilt angles. It does not seem practical to introduce storage of heat, except at very limited levels, due to the high cost of a storage system.

The costs given are tentative: firmer estimates need a site-specific evaluation. Nevertheless, the costs would appear to be considerably lower than for a purely solar power station with a back-up fuel system for the same power input.

The configuration proposed in this paper is amenable to variations to optimise costs and performance, which need to be studied. Significant benefits could accrue from design optimisation of the collector field. For instance, flat plate collectors could be used in the low temperature range of feed water heating, say upto $70^{\circ} \mathrm{C}$. This could be cheaper and make better use of diffuse radiation as compared to concentrating collectors. In the intermediate temperature range, evacuated tube collectors could be considered. Parabolic trough collectors could be used mainly for the high temperature range. Another variation which may be considered is to directly heat the feed water through the collectors without the use of a heat transfer fluid. This may be possible in the LP heater sections, where the pressures and temperature are lower.

In conclusion, it would appear that the present proposal to integrate a solar collector field with a thermal power station has several potential benefits and is technically feasible at currently available levels of technology. Further, detailed site specific studies need to be carried out in order to examine all the technical problems and the techno-economic aspects. In the present fragile scenario with fossil fuels, such studies, to introduce nonpolluting renewable energy sources, need to be taken up on priority so that an early demonstration can be taken up.

The author would like to thank the Karnataka Power Corporation for data on the thermal power plant and for its "pioneering spirit" towards technologies for renewable energy. 
Table A1. Basic characteristic of SEGS I-IV.

\begin{tabular}{|c|c|c|c|c|c|c|c|c|}
\hline \multirow[b]{2}{*}{ Plant } & \multirow{2}{*}{$\begin{array}{c}\text { First } \\
\text { operating } \\
\text { year }\end{array}$} & \multirow[b]{2}{*}{ Status } & \multirow{2}{*}{$\begin{array}{c}\text { Capacity } \\
\text { (MWe net) }\end{array}$} & \multirow{2}{*}{$\begin{array}{l}\text { Solar } \\
\text { temp. } \\
\left({ }^{\circ} \mathrm{C}\right)\end{array}$} & \multirow{2}{*}{$\begin{array}{c}\text { Field } \\
\text { size } \\
\left(\mathrm{m}^{2}\right)\end{array}$} & \multicolumn{2}{|c|}{$\begin{array}{c}\text { Turbine cycle } \\
\text { efficiency }\end{array}$} & \multirow{2}{*}{$\begin{array}{c}\text { Annual } \\
\text { output } \\
\text { (MWh net) }\end{array}$} \\
\hline & & & & & & Solar & Boiler & \\
\hline I & 1985 & Operational & 13.8 & 307 & 82,960 & $31 \cdot 5^{*}$ & - & 30,100 \\
\hline II & 1986 & Operational & 30 & 315 & 165,376 & $29 \cdot 4$ & $37 \cdot 3$ & 80,500 \\
\hline III & 1987 & Operational & 30 & 349 & 203,980 & $30-6$ & $37 \cdot 4$ & 85,050 \\
\hline IV & 1987 & Operational & 30 & 349 & 203,980 & $30-6$ & $37 \cdot 4$ & 85,050 \\
\hline V & 1988 & Construction & 30 & 349 & 233,120 & $30 \cdot 6$ & $37 \cdot 4$ & 91,820 \\
\hline VI & 1988 & In design & 30 & 390 & 188,000 & 37.5 & $39 \cdot 5$ & 90,575 \\
\hline VII & 1989 & In design & 30 & 390 & 183,120 & $37 \cdot 5$ & 39.5 & 94,410 \\
\hline
\end{tabular}

* Including natural gas superheat

\section{Appendix A}

The basic characteristics of four operating solar power plants in California and three future plants (Jaffe et al 1987) are shown in table A1.

The basic component of the Luz solar field is the Solar Collector Assembly (SCA). Each SCA has its own parabolic trough solar collector, positioning system and local control system. The parabolic trough solar collector is a mirrored glass reflector which focusses direct radiation on an efficient evacuated receiver, or heat collection element (HCE). Luz Industries has developed three generations of its solar collector assembly, LS-1 (Luz System 1), LS-2 and LS-3. Table A2 gives the characteristics of each SCA type.

Table A2. Characteristics of solar collector assemblies.

\begin{tabular}{lccc}
\hline & LS-1 & LS-2 & LS-3 \\
\hline Area $\left(\mathrm{m}^{2}\right)$ & 128 & 235 & 545 \\
Mirror segments & 64 & 120 & 224 \\
Aperture (m) & $2 \cdot 55$ & $5 \cdot 0$ & $5 \cdot 76$ \\
Length (m) & $50 \cdot 2$ & $47 \cdot 1$ & $95 \cdot 2$ \\
HCE diameter (m) & 0.042 & 0.070 & 0.070 \\
Average focus distance (m) & 0.94 & 1.84 & $2 \cdot 12$ \\
Distance between rows (m) & $7 \cdot 3$ & $12 \cdot 5$ & $17 \cdot 3$ \\
Optical efficiency & 0.734 & 0.737 & 0.772 \\
HCE emittance & $0 \cdot 3$ & 0.24 & 0.15 \\
$\quad$ (at temperature, $\left.{ }^{\circ} \mathrm{C}\right)$ & $(300)$ & $(300)$ & $(350)$ \\
HCE absorptivity & 0.94 & 0.94 & 0.97 \\
HCE transmissivity & 0.95 & 0.95 & 0.965 \\
Mirror reflectivity & 0.94 & 0.94 & 0.94 \\
Peak collector efficiency (\%) & 66 & 66 & 68 \\
Annual thermal efficiency (\%) & & & \\
$\quad$ (collector plane) & 51 & 50 & 53 \\
Used in SEGS & I, II & III-IV & VII \\
\hline
\end{tabular}

\section{References}

Jaffe D, Friedlander S, Kearney D 1987 The Luz Solar Electric Generating System in California, Luz Report Mani A, Rangarajan S 1982 Solar radiation over India (New Delhi: Allied Publishers)

Schroeder R C 1991 Span (January) 